\title{
The Story Behind the Economics: Providing Context by Using Story-telling to Illustrate Economic Theory
}

\author{
Mariam Khawar \\ Elmira College
}

Using the art of narrative to tell a story can be helpful when students become overwhelmed with mastering the technical aspects of economic theory and have a hard time 'finding the forest for the trees'. This paper reviews recent critiques of economics that have some leading voices in the discipline advocating for broader perspectives which incorporate both the content and methodology of other disciplines. Building on this argument, the paper will discuss two narrative assignments that the author regularly uses in a class on international trade and finance.

\section{INTRODUCTION}

Economics appears to be more on the defensive as of late. This time however, many of the critiques stem from within the discipline, a phenomenon that is harder to brush off as simply another disgruntled attack from an "outsider" whose discipline resents the status and prestige that economists enjoy. ${ }^{1}$ From popular bestsellers to thoughtful commentaries in the discipline's most widely read journals, economists are questioning the discipline's single-minded focus on mathematical abstraction and its increasing disconnect from its philosophical roots. ${ }^{2}$ Additionally, the financial crisis of 2008 forced economists to reconsider the theoretical underpinnings of many of their models and the discipline endured a lot of heat for its failure to predict the timing and depth of the Great Recession. ${ }^{3}$

The critiques from outside academia, in respected publications, have also been consistent and loud. A 2016 article in The Economist refers to the "profession's "mathiness" and "model-mania", adding "Economists are good at reducing a complicated world to a few assumptions, then adding bells and whistles to make their models more realistic. But problems arise when they mistake the map for the territory", (The Economist, 2016). Last year, The Economist even felt the need to start a series of articles "on the profession's shortcomings", the first one focusing on explanations by economists regarding the causes of economic growth, (The Economist, 2018). In an interesting parallel, the news magazine simultaneously ran a series of briefs titled "Liberal Thinkers", as if reminding the profession of its roots in philosophy. The first one titled "The father of liberalism - Against the tyranny of the majority", focused on the writings of John Stuart Mill and appeared in the August $4^{\text {th }}, 2018$ print edition.

As far back as 1996, an article in The New Yorker lamented, "Mathematics, which used to be considered a valuable but subordinate aid to intuitive thought, now dominates economics to such an extent that good ideas are often ignored by professional economists simply because they are not written down in pages of algebra. Similarly, bad ideas that are expressed in clever mathematical models tend to survive even if they are contradicted by the evidence." (Cassidy, 1996). 
One audience that economists tend to ignore, perhaps even scorn, is that comprised of other social scientists. As Rodrik (2015) eloquently points out, the graduate school qualifications and training required to enter the economics 'guild' are such that other social scientists who are lacking that training, are unable to comprehend most papers in economics. Many of us can attest to the fact that even for economists who have had the requisite training at elite institutions, several decades away from the application of mathematical theory on a daily basis will require the abstract mathematics muscle in the brain to be reconditioned before reading some theoretical papers in the American Economic Review. Rodrik adds that this "comprehensibility barrier... heightens noneconomists' suspicions about the profession: the math makes it seem as if noneconomists have withdrawn from the real world and live in abstractions of their own construction", (Rodrik, 2015, p.30).

It is perhaps the culmination of all of these factors, a perfect storm of sorts - that has forced this introspective examination on the part of the discipline. Regardless of the reasons, it is to be commended and encouraged, and one way to do that is to set an example for the current generation of economics undergraduates.

\section{THE STUDENT EXPERIENCE OF ECONOMICS}

In all but the most selective colleges and universities, economics attracts fewer majors than business administration. Students want to graduate with a degree in a subject that 'sounds' like it will land them a job right away. According to the most recent data available from the National Center for Education Statistics (2018), one out of every five bachelor's degrees completed is currently in business administration. Hence, many students have at least some exposure to economics in one way or the other. The experience of the typical undergraduate student (at non-elite institutions) consists of the following stages:

1. Confusion: most students wander into an economics course believing it to be an extension of their marketing/management/business class and are surprised to find out that it is something entirely different.

2. Dismay: when they begin to encounter their first set of equations and graphs which tend to make up most economics models and realise that math, that dreaded four letter word, is going to be heavily utilised.

3. Frustration: as the semester progresses, a good number of students will continue to struggle with understanding concepts and using models because of weak quantitative skills. Since the theories are built around mathematical models, these students have a hard time comprehending and applying them. Thus, they fail to understand many of the basic concepts, leading to frustration on their part.

4. Resignation: most students lose interest in the subject and are resigned to the fact that they just have to 'get it over with'. The math serves to obfuscate rather than clarify concepts for them and many of them have not been able to find the forest for the trees.

5. Confusion: by the end of the course most students are scratching their heads and wondering at the relevance of what they have just spent a semester studying. In particular, the business administration students find little that they can relate to and apply to their own discipline which relies heavily on case studies and real-world examples to illustrate ideas.

The above description might be a tad bit exaggerated, but it is not that far from depicting a realistic scenario. Students have spent a frustrated semester and are likely to go to great lengths to avoid taking another economics course if possible. Meanwhile, as professors and guides to the discipline, we have squandered an excellent opportunity to showcase it, introduce students to its versatility and applicability and attract them to the major. This is what one would categorise as a lose-lose situation.

Not everyone agrees that making economics relevant to undergraduate students is either necessary or desirable. Rubinstein states "My impression is that the problem lies in the unrealistic expectations students have of economics, rather than whether economics is taught in a practical way." He further adds, "The competition for students pushes departments of economics to reinforce students' illusions" and that 
"Conventional textbooks are designed to look like brochures for investment firms. Anecdotes and newspaper quotes are used to stimulate the student's interest and convince him that the textbook's contents are indeed relevant.", (Rubinstein, 2017, p. 168).

On the other hand, Rubinstein is open to the idea of pluralism in economics, advocating for the addition of works by Adam Smith and Karl Marx while cautioning that "few professors of economics are capable of teaching it properly", (Rubinstein, 2017, p. 169). He also pushes for less use of mathematical precision but curiously concludes that this will diminish students' perception of the practical application of economics and as a result the popularity of the major might suffer.

One cannot help but wonder whether the student population that Rubinstein is referencing - one that will relate less to economics if it becomes less mathematical - must be substantially different than the one taught by the majority of economics professors around the country. In elite colleges and universities, economics remains a popular major as most of these institutions do not offer a major in business administration (hence many students who want to pursue careers that the typical business administration major might aspire to, major in economics since that is the most relevant option). However, as indicated earlier, in less selective institutions which constitute the majority of higher education, business administration majors outnumber economics majors by several magnitudes. It is hard to imagine the typical student in such an institution turning away from economics because of its decreased emphasis on math. Instead it is more likely, that if economics were to embrace the pluralistic methodology that both Rodrik and Rubinstein refer to, if it were to incorporate more stories and anecdotes (case studies) that help students place issues in context, it might just make itself more attractive as a discipline. ${ }^{4}$

\section{THE STORIES BEHIND THE ECONOMICS}

So, what are the stories behind the economics? There are in fact, multiple interpretations of what 'story-telling' in relation to economics consists of. Some view models themselves as a form of storytelling. Both Rodrik and Rubinstein compare economic models to fables. As Rodrik states, "A fable makes little effort to be realistic or to draw a complete picture of the life of its characters. It sacrifices realism and ambiguity for the clarity of its story line", (Rodrik, 2015, p. 19). He further points to the stylised behavior of the main characters in fables as well as the causal nature of relationships and the plot line. Lastly, he reminds us of the interpretative function of fables and the fact that they can be applied to a variety of settings, just like models in economics. Rubinstein goes further by believing that, "A good model is, for me, a good story between human beings (not computers and bees)", (Rubinstein, 2017, p. 166). While drawing parallels between the limitations of both economic models and stories, he cautions that neither models nor stories are tools for making predictions and that they are not meant to be 'useful' in the way that most people assume or want them to be. Instead, the utility according to him, of each framework is realised when it "inspires new ideas and clarifies situations and concepts", (Rubinstein, 2017, p. 167). Lastly, Rubinstein believes that neither models nor stories are testable; with the former we should be focused on the validity of the assumptions rather then the predictions and with the latter our concern should be in determining whether the basic plots or scenarios are realistic (Rubinstein, 2017, p. 167).

Another perspective on story-telling can be found in Morson and Schapiro's discourse on economics and the humanities (Morson and Schapiro, 2017). While reiterating some of the criticisms heard previously about economists' single-minded focus on model building and mathematical precision (the "hedgehog" mindset), the authors also raise the issue of economic imperialism - the application of economic models and methodology to problems and issues outside the 'domain' of economics (Morson and Schapiro, 2017, p. 61). ${ }^{5}$ While I don't necessary believe that this domain needs to be precisely defined, there is a follow-up argument by Morson and Schapiro that is worth examining. The authors contend that economists should be more like foxes (as opposed to hedgehogs) by embracing theories from a wider variety of disciplines, notably other social sciences and the humanities. ${ }^{6}$ Instead of 'taking over' these fields, they should be incorporating their ideas and methodologies to complement their own. In particular, they believe that a key ingredient that is missing from economists' formulations of models is 
the influence of culture which is where sociologists and anthropologists have much to offer, (Morson and Schapiro, 2017, pp. 265-70). ${ }^{7}$

The humanities are the primary focus of the authors' pitch and a case is made to include the study of literature in the economist's toolkit to aid in the development of wisdom, good judgement, morality, empathy and ethical and cultural considerations. Unfortunately, the authors fall short of drawing any meaningful connections between economics per se and the humanities. Beyond the suggestion that reading great literature (War and Peace and Anna Karenina are favourites) will help cultivate the above considerations, there is no practical advice as to how to incorporate novels into an economics curriculum. In fact, much of the argument can be viewed as a (sensible) case for the overall inclusion of literature in a general education curriculum, one that many of us would not disagree with.

A third, and arguably more influential, viewpoint is articulated by Robert Shiller most notably in his presidential address at the American Economic Association meetings in 2017. Shiller advocates the study of what he refers to as "narrative economics" which he defines as, "the study of the spread and dynamics of popular narratives, the stories, particularly those of human interest and emotion, and how these change through time, to understand economic fluctuations", (Shiller, 2017, p. 967). The narratives that he is referring to are stories in the media, both news and social, about significant events that affect people's lives or their emotions. Their importance arises from serving as "major vectors of rapid change in culture, in zeitgeist, and ultimately in economic behaviour, (Shiller, 2017, p. 972).

Unlike Morson and Schapiro (2017), Shiller cuts to the chase right away and elaborates that the type of study (of narratives) he is referring to is quantitative, ".... a class of mathematical models for some of these determinate and known causes of the path of narratives, quantifying the dynamics of narratives.", (Shiller, 2017, p. 968). In true hedgehog fashion, he rejoices in the conviction that "Research in economics is already on its way to finding better quantitative methods to understand the impact of narratives on the economy", (Shiller, 2017, p. 998). One of the methods that Shiller is referencing is textual analysis which he believes can be advanced by researchers "if they use multiple research assistants with explicit instructions to read narratives and to classify and quantify them for their essential emotional driving force", (Shiller, 2017, p. 999). Hedgehog anyone? ${ }^{8}$ Shiller's conception of narrative economics is on par with the multiple applications of economics to various fields such as sports economics, environmental economics, law and economics etcetera. In an interesting parallel, the humanities which are facing their own crisis of relevance, are moving closer to the economist's domain of quantitative analysis using the tools of the digital humanities. At a digital humanities workshop that I had the opportunity to participate in last year, much of the focus was on tools to conduct textual analysis of historical and literary texts. Unbeknownst to each other, economists and humanists might find their domains overlapping, although not in the unified ways that Morson and Schapiro (2017) hope for.

\section{BRINGING STORIES INTO THE CLASSROOM}

As the previous section noted, there are several perspectives of story-telling in the context of economics. Can we use these interpretations of story-telling as tools to help students understand difficult economic concepts and to provide an example of more 'foxlike' economic investigation? In what follows, I will describe two texts that I have used to fulfil these roles in an economics class.

At my institution, a small, private liberal arts college, International Trade and Finance is an upper level economics elective typically taken by students satisfying three types of requirements: an elective for the economics major, an elective for the finance major or as a requirement for the international business major. The class is challenging for most of these students as it relies heavily on mathematical models of international trade (Ricardian, specific-factors, Heckscher Ohlin) and mathematical models of international finance (the monetary and asset models of exchange rate determination). Graphs, equations, and formulae are extensively used and most textbooks chapters move rapidly from simpler to more advanced theoretical concepts.

To the student, especially one who is not planning on pursuing economics at the graduate level (and for our type of institution at least, it is an increasingly small number who do), the material can appear as a

Journal of Applied Business and Economics Vol. 21(1) 2019 
succession of increasingly complex formulations of models, whizzing by at breakneck speed. Once again, it is difficult to see the forest for the trees. At the same time, rhetoric about international trade and protectionism abounds and it is increasingly important to have a thorough understanding of the issues involved, as the stakes are high. Hence, in addition to the standard trade text book, my students read two supplementary texts, a story designed to help understand the basic ideas of comparative advantage and an investigative style narrative which incorporates a wide variety of issues pertaining to international trade and protectionism. Lastly, students complete a research project modeled on the investigation, and present it to the class in the form of a narrative using mapping tools employed by the digital humanities.

The first book, The Choice: A Fable of Free Trade and Protectionism by Russell Roberts is, as the title suggests, a stylised account of the virtues of free trade and the perils of protectionism. The basic premise of the story is borrowed from the film It's a Wonderful Life. The ghost of David Ricardo, visits the owner of an American television manufacturing plant who is plagued by doubt on the eve of a speech he has to give for a candidate running for political office. Ricardo shows Ed (the owner) what the future would be like without free trade, including the fate of his children and grandchildren (fewer opportunities in the protectionist world), the economic progress of his hometown (stagnant) and the state of technology (little progress). He also shows him an alternative free trade world with expanded choices and technological and social progress. Throughout the story, Ed and Ricardo engage in arguments and conversation meant to explain to the reader the gains from comparative advantage in the long run, even though it may cause short-term pain, especially to workers in import-competing industries. Several chapters are devoting to explaining protectionism and the welfare and efficiency losses it imposes. ${ }^{9}$

The book, as its titles claims, is a fable and is not meant to depict every facet of the real world. As such, some of the arguments are simplistic and overlook many real-world complexities that make a significant different to the outcomes, such as job mobility and the difficulties of retraining and acquiring new skills. As long as that caveat is acknowledged and taken into consideration, it is an excellent vehicle for understanding some of the basic models of international trade. Students unanimously report that the book aids them in their understanding of these concepts, although they do get a bit tired of the repetitiveness of the message that it is delivering. Several students state that they have read segments of the book to family members (parents!) to successfully explain the arguments for free trade.

The second book, Travels of a T-Shirt: An Economist Examines the Markets, Power and Politics of Free Trade by Pietra Rivoli is a fascinating look at the political economy of international trade. Rivoli is the quintessential economist-fox. Starting with the history of cotton-growing in the deep South, Rivoli takes the reader through the economic, political, protectionist, social, cultural, environmental and ethical issues surrounding global trade. The narrative includes numerous interviews with key participants in the process from farmers in the South, to factory managers in China, political activists in Washington, DC and entrepreneurs of recycled t-shirts in east Africa. Meticulously researched and well-written, it is an engaging narrative on a topic that deals with a sweeping array of issues and does it in a way that is accurate, and even-handed. Students however, do tend to 'like' this book less than The Choice, which is shorter and more easily digestible. Perhaps this has something to do with them having to spend much more time reading and responding to the discussion questions (see next paragraph), which likely influences their preferences.

To ensure that students read both books and are prepared for in-class discussions, they are assigned short answer essay questions to complete and turn in for a grade ahead of time (see appendix for the assignments for each reading). To facilitate discussion and ensure wider participation, students are divided into pre-assigned groups to discuss each question. The groups are mixed up and students are rotated throughout so that each set of questions is discussed with a new set of people. A different spokesperson reports back to the whole class on the group's conversation, at the end of each round of discussions. This generally makes for a lively, participatory atmosphere, ensures that almost everyone is involved in the discussion to the greatest extent possible and allows for an exchange of ideas and views that are not typically part of economic theory classes. 
An end of class survey done a couple of years ago showed that most students felt that Travels of a TShirt helped their understanding of concepts covered in the course. TABLE 1 summarises student responses:

TABLE 1

EFFECT OF TRAVELS OF A T-SHIRT BOOK ON STUDENT UNDERSTANDING OF CONCEPTS

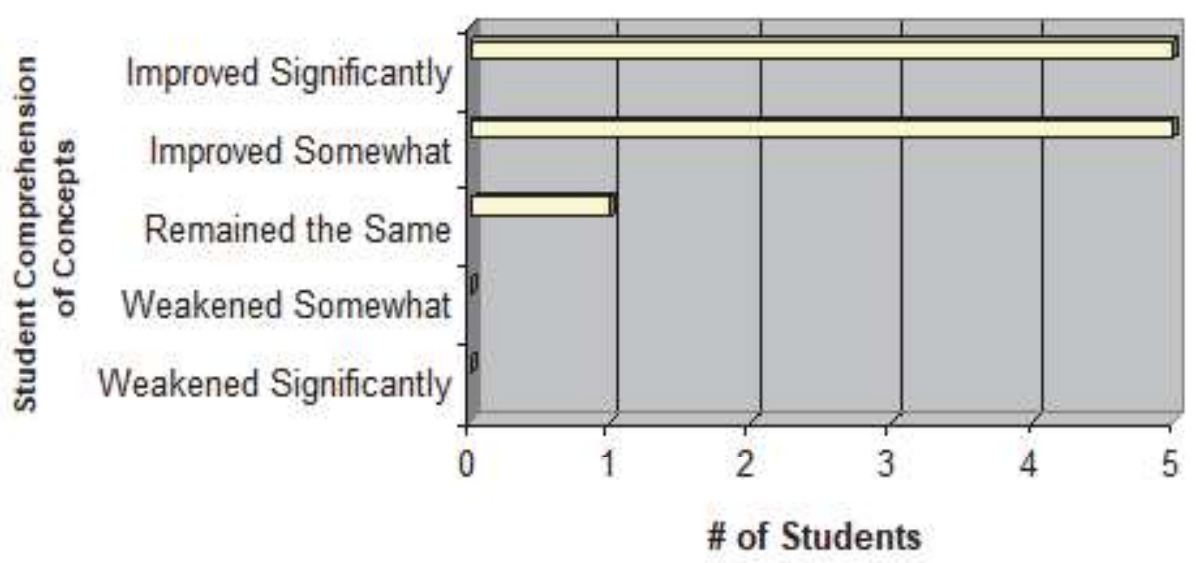

Students also reported both books, The Choice and Travels of a T-Shirt, as being the more enjoyable components of the course (on par with lectures!?), as TABLE 2 shows.

TABLE 2

\section{EXTENT TO WHICH COURSE COMPONENTS WERE ENJOYED}

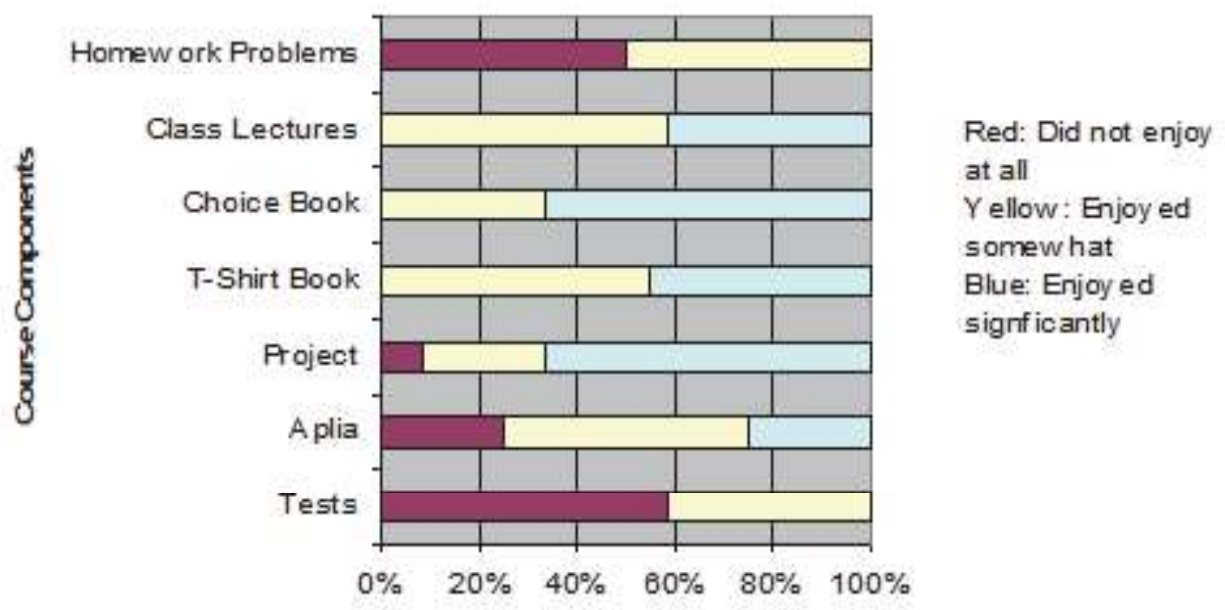

Finally, students reported both narratives as contributing either 'somewhat' or significantly to their understanding of trade theory concepts, as illustrated in TABLE 3. 
TABLE 3

CONTRIBUTION OF COURSE COMPONENTS TO UNDERSTANDING OF TRADE THEORY

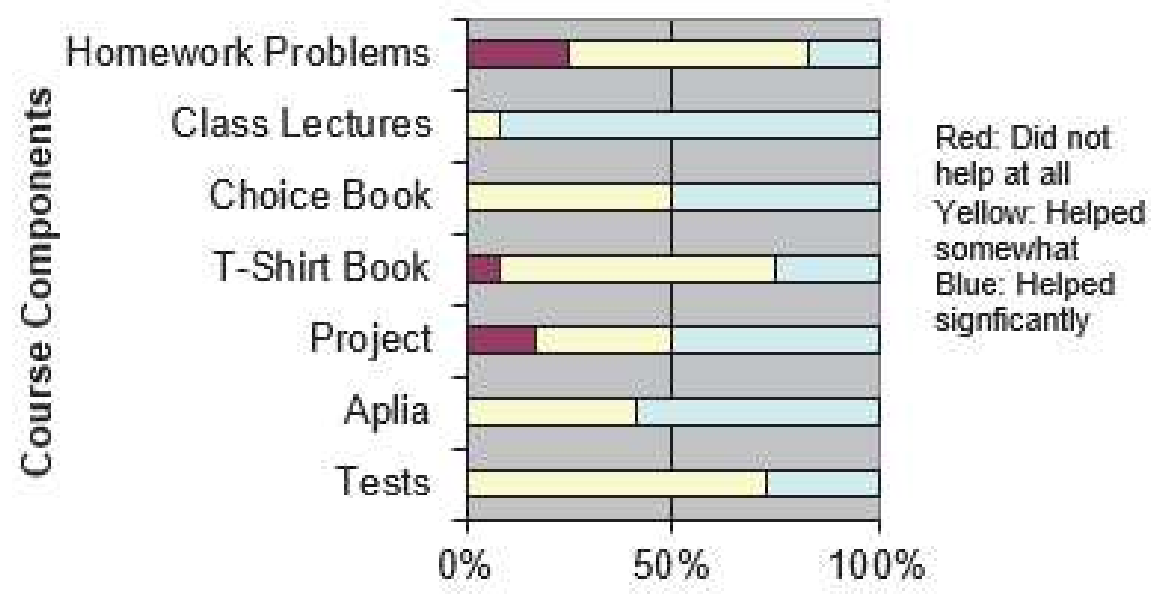

The third component of this endeavour is to get students to practise some foxiness of their own. A group research project along the lines of Travels of a T-Shirt is assigned, which requires students to pick any product that has a global trade component to it. The task is then to track it from inception to distribution by researching its product markets (stages of production), labour markets, trade barriers, government intervention and any other social, environmental, political or ethical issues associated with it. The students are told they will be 'virtual' travellers which means they are doing the majority of their research online using websites for corporations, governments, international organisations and of course scholarly sources.

In the most recent iteration of this project, I added a requirement that the project had to be presented using a mapping tool, instead of the traditional PowerPoint format that had been the norm before and that most students are used to. The mapping tool is one that I learned about while attending a workshop on digital humanities last fall and it has the advantage of incorporating a spatial and geographical component to research, which is perfect for a project that involves many cross-border issues. This also helped to provide a sense of narrative but that depended to some extent on how well each group utilised the tool. Students did report some frustration with the software which could only be accessed through one account, and this made it difficult for group members to contribute unless they were all gathered together in one place. On the whole though, the final projects went a long way towards including more than just the economics of trade, and students developed a good sense of the complexities of the issues involved by having a story to tell.

While direct assessments of these three tools (the two books and the project) were not performed, student feedback and the scores on grading rubrics of the components indicate that incorporating some form of story-telling is a useful and welcome addition to the standard economist's toolkit of mathematical theory and models, especially at the undergraduate level. It also exposes students to the larger context in which economic behaviour and decision-making resides, providing a wider perspective to enrichen their understanding of complex phenomena.

Mathematics will always be a part of economic modeling, and certainly provides a useful set of tools for economists to develop models to explain, understand and predict outcomes. The key however, is to strike the right balance between mathematical techniques and narrative style, especially if economists desire to be more widely understood. Acknowledging the contexts - social, political, historical - in which economic activities take place, doesn't diminish the importance of models. Instead, it helps us tell a more compelling story. 


\section{ENDNOTES}

1. A couple of statements by Ariel Rubinstein summarise this view: 1. "Critiques by non-economists often leave the impression that they have misunderstood what economists do." 2. "One needs to be an outsider to criticize economics, but one needs to be an economist to do it sufficiently well so as not to be drawn astray by stereotypes." (Rubinstein, 2017, p.163).

2. Recent best sellers addressing this issue include Cents and Sensibility: What Economics Can Learn from the Humanities by Morson and Schapiro and Economics Rules: The Rights and Wrongs of the Dismal Science by Dani Rodrik. Recent articles which critically examine the predominant methodology used by economists include "Comments on Economic Models, Economics, and Economists: Remarks on Economic Rules by Dani Rodrik" by Ariel Rubinstein which appeared in the Journal of Economic Literature and "Narrative Economics" by Robert Shiller which was published in the American Economic Review, the discipline's premier journal. The paper also formed the basis of the presidential address at the annual meeting of the American Economic Association in January 2017, the discipline's premier professional gathering.

3. An example of this can be found in "The Crisis in Economic Theory: A Review Essay" by Kevin Hoover, which was published in the Journal of Economic Literature in 2016.

4. This assumes of course that making economics more attractive is a desirable goal. Some economists with the 'guild' mindset might subscribe to the notion that the mathematical complexity of economics leads to a judicious self-selection on the part of those who choose to study economics which should not be tampered with.

5. I confess that in this matter I too, am guilty as charged. I start the first day of my principles of microeconomics course by suggesting that economics can be applied to any problem and any situation that the students can come up with. Most principles textbooks include headings such as "Economics is everywhere" to convince students of the relevance of the subject they are about to engage in. I do however, follow up my statement with the caveat that economics provides one perspective on an issue and that there are many other ways of viewing the same problem. Partly this is out of sensitivity to the other social science majors that have accidently found their way into the course; I don't want to provide an example of the hubris that economists are often accused of.

6. It should be noted that this point has been made almost two decades earlier by Andrew Kamarck in his book "Economics for the Twenty-first Century: The Economics of the Economist-fox".

7. My own modest attempt to be more of an economist fox can be found in "The Geography of Underdevelopment: Institutions and the Impact of Culture", (Khawar, 2017).

8. In defense of Shiller and other economists, it should be noted that other disciplines can be just as singleminded in believing that their discipline's methodology and world-view is universally applicable. A classic example of hedgehog behavior from another discipline is provided by Morson and Schapiro with this famous quote from The Communist Manifesto, "The history of all hitherto existing society is the history of class struggles." (Morson and Schapiro (2017, p.58). A bit reductionist perhaps?

9. I taught this class in 2016 which was an election year. The debates on trade and protectionism that took place on the national and political stage were an invaluable 'real-time' teaching tool and the parallels to the setting in The Choice were eerily similar. 


\section{REFERENCES}

A Less Dismal Science (2016, July 16). The Economist.

Cassidy, J. (1996, December 2). The Decline of Economics. The New Yorker.

Hoover, K. D. (2016). The Crisis in Economic Theory: A Review Essay. Journal of Economic Literature, 54(4), 1350-61

Kamarck, A. (2001). Economics for the Twenty-first Century: The Economics of the Economist-fox. London: Routledge.

Khawar, M. (2017). The Geography of Underdevelopment: Institutions and the Impact of Culture. New York: Palgrave Macmillan.

Morson, G.S., \& Schapiro, M. (2017). Cents and Sensibility: What Economics Can Learn from the Humanities. Princeton; Oxford: Princeton University Press.

National Center for Education Statistics (n.d.). Retrieved from https://nces.ed.gov/fastfacts/display.asp?id=37

Rivoli, P. (2014). Travels of a T-Shirt in the Global Economy: An Economist Examines the Markets, Power and Politics of World Trade. Hoboken, New Jersey: Wiley.

Roberts, R. (2006). The Choice: A Fable of Free Trade and Protectionism. New York: Pearson.

Rodrik, D. (2015). Economics Rules: The Rights and Wrongs of The Dismal Science. New York: W.W. Norton.

Root and Branch (2018, April 14). The Economist.

Rubinstein, A. (2017, March). Comments on Economic Models, Economics, and Economists: Remarks on Economics Rules by Dani Rodrik. Journal of Economic Literature, 55(1), 162-72.

Shiller, R. J. (2017). Narrative Economics. American Economic Review, 107(4), 967-1004.

The Father of Liberalism - Against the Tyranny of the Majority (2018, August 4). The Economist. 


\section{APPENDIX}

The Choice - A Fable of Free Trade and Protectionism (3e) by Russell Roberts

\section{Reading and Writing Assignment}

Read the whole book, cover to cover. Make sure you read Chapter 17 at the end as well since it contains explanatory notes on each chapter.

Write a brief paragraph on each of the following (typed) to prepare for the discussion. Upload your assignment by the due date.

1. Which trade model(s) seem most representative of the world depicted by Roberts? Why? Use specific evidence from the book to justify your answer. More than one model may be representative at times.

2. Is Roberts even-handed in his treatment of free trade, i.e. does he discuss both pros and cons equally? Provide specific examples from the text to back your answer.

3. Do you find Roberts' arguments concerning the effects of free-trade or no-trade (autarky) convincing? Why or why not? Reference the text when discussing specific issues.

4. In what ways might the 'real world' differ from the fictional world depicted by Roberts in the book?

5. Summarize briefly the events that take place in the chapters that you were specifically assigned.

6. Discuss two issues each from those chapters that you gained the most insight from. It could be because you strongly agree or disagree, find them particularly significant or controversial, or other reasons.

\section{Additional Discussion Questions:}

1. What primary myth of yours did the book debunk?

2. Who propagates these myths? Why? Who benefits? Who loses?

3. What IS "the Choice"? (Where does the author get the title of the book)

4. Dave shows Ed what life would be like in 2001 without any protectionism. But America is not truly the free trade image that Dave reveals. Where on a scale of 1-10 do you think America is now in terms of Dave's pure vision of free trade in America?

5. Name an economic, social, or political situation in the US that Dave would not look upon favourably.

\section{The Travels of a T-Shirt in the Global Economy (2e updated) by Pietra Rivoli}

\section{Reading and Writing Assignment}

As you read the book keep these questions in mind. You can jot down notes or responses to them as you read. Use evidence from the book to support your answers, keep them concise and clear but make sure and discuss all the relevant points pertaining to the questions.

Proof-read your essays and check for spelling, grammar etc. as if you were writing a paper. I will grade with those considerations in mind as well. See posted Rubrics on how the responses will be graded. In addition to answering the questions, read the book critically and underline or write notes about sections or issues that you would like to raise in the discussion and/or have questions about.

The Preface and Epilogue contain important updates from 2009-14 so make sure you don't skip them (:) Enjoy the book! 
$\underline{\text { Preface }}$ book.

Read the preface in the beginning but answer the following questions after you have finished the

1. Rivoli is concerned that the story she tells - the travels of a t-shirt is "a lesser mode of inquiry......not up to the task of illuminating the complex issue of global trade". After reading the book, how effective do you think this methodology was in conveying the issues? What are the advantages and disadvantages of this approach?

2. "There is no such thing as an objective storyteller" according to Rivoli. What biases are apparent in Rivoli's account? Do you think she overcame them in the course of the narrative? Explain.

\section{Prologue and Chapter One}

1. What three reasons does Rivoli give for America's global dominance in the cotton industry?

\section{Chapter Two}

1. Why were the requirements of farm labour in the US cotton industry difficult to fulfill through the labour market?

2. How was this problem of farm labour eventually resolved?

3. Why did China and India not develop a globally competitive cotton industry?

4. How did US cotton farmers continue to be insulated from the uncertainties of the labour market after the demise of slavery?

\section{Chapter Three}

1. What factors lead to the demise of Ned Cobb as a cotton farmer?

\section{Chapter Four}

1. In 2006 what was the magnitude of US government cotton subsides? What effects did they have globally?

2. In addition to the removal of subsidies, what factors does Rivoli feel are critical for poorer countries to compete effectively with US cotton producers?

\section{Chapter Five}

1. What are some of the challenges that Tao Yong Fang, manager of the Number 36 factory, faces in China's move from central planning to capitalism?

2. Explain the perspective that China's current global dominance in textile and apparel is 'a failure for American trade policy, a failure for American workers, a failure for American consumers, and a failure especially for Chinese workers'?

\section{Chapter Six}

1. Trace the geographical path of the global textile industry starting from Great Britain and ending in China. What parallels (similarities) are present in the production process, especially as it relates to labour, in each region?

\section{Chapter Seven}

1. What factors make "China's lead in the race to the bottom in textiles apparel....the same yet different from that of her predecessors"?

2. What factors were important in the decision of millions of rural Chinese women to leave their villages in favour of factory work in the cities? 


\section{Chapter Eight}

1. In what ways does Rivoli see the forces of global capitalism and labour activism working together 'in improving the human condition'?

2. Rivoli states that trade enables "a race to the top of another sort". What is she referring to?

\section{Chapter Nine}

1. How has trade with China affected jobs in the US textile industry? How would Roberts (The Choice) respond to this complaint?

\section{Chapter Ten}

1. Discuss at least three factors that Rivoli mentions as the reasons for the political influence of the US textile industry.

2. What unintended consequences resulted from the numerous VERs that the US imposed on various countries?

\section{Chapter Eleven}

1. What are the 'alphabet armies'? Why does Rivoli refer to them as their own worst enemy?

2. What perverse consequences have arisen from the imposition of quotas by the US?

3. According to Rivoli why do Americans, the vast majority of whom are not textile workers, tolerate the maze of protectionism in the textile industry?

\section{Chapter Twelve}

1. Why does Rivoli find the argument that the MFA (multi-fiber agreement) has stood in the way of developing countries, not compelling?

\section{Chapter Thirteen}

2. What is the 'snowflake factor' in the context of used T-Shirts? How does it provide a niche for small businesses?

3. How did the same factors that destroyed the US' comparative advantage in textile give rise to an advantage in the recycling of T-Shirts?

\section{Chapter Fourteen}

1. What types of price discrimination take place in the pricing of recycled t-shirts?

2. What part of the recycling process is close to a perfectively competitive market? Why?

\section{Chapter Fifteen}

1. Rivoli argues that the mitumba trade is beneficial to African countries. In what ways? Do you agree? 


\section{Epilogue}

1. When Rivoli investigated the US used clothing industry, she believes that it was the first time she encountered a textbook version of perfect competition in her t-shirt's travels. How has this industry evolved when she revisited Ed Stubin in 2014?

2. By 2014 what unintended consequences were being realized by the 'yarn-forward' rule in the still-negotiated TPP (Trans Pacific Partnership)?

3. The factory fire in Bangladesh in 2013 illustrated that the 'race to the bottom' had changed. In what ways?

4. "The poor and powerless often suffer more from the suppression of competitive markets than from competition itself". Discuss what Rivoli is referring to in the context of West African cotton farmers.

5. How did West Texas farmers transform a challenge (wind and drought) into an economic opportunity?

6. How did the 2014 US Farm Bill circumvent the WTO ruling on agricultural subsidies? 